\title{
Prevalence of psychomotor retardation and its relation to the sensory profile in preschool children
}

\author{
Laura Delgado $^{1}$, Rebeca Montes ${ }^{1}$, Jose Antonio Prieto ${ }^{1}$
}

DOI: http://dx.doi.org/10.7322/jhgd.122815

\begin{abstract}
:
The psychological and motor development of typically developing preschool children is usually not tracked in the educational environment. The aim of the study is to determine the prevalence of psychomotor retardation and the relationship between psychomotor development and sensory integration processes. The sample included 66 children from preschool, with a mean age of 4.2 years. It applied the Observational Scale of Development in its short version (EOD-B as its Spanish original term) and the Sensory Profile (SP). The ANOVA revealed a strong association between the presence of psychomotor and sensory processing disorders $(p=0.001)$. In addition, the data revealed a high prevalence of regulatory disorders in the sensory profile (30\%) and psychomotor retardation (20\%). The results open new lines of research and intervention in psychomotor development within the educational environment
\end{abstract}

Keywords: psychomotor development, sensory integration, preschool education.

\section{INTRODUCTION}

Childhood is a critical period in ontogeny, and the psychomotor settlement at this stage is the basis for future development. As a result, delays in early childhood can have lasting effects ${ }^{1}$. Early detection of problems in the motor development of children would allow for knowledge of their limitations and restrictions, enabling intervention through adjustments in the education program, so that the child can reach full development ${ }^{2}$. In this sense, perceptual-motor alterations in the first years of life can have an impact on the school performance of children, inevitably affecting their overall development ${ }^{3}$.

\section{Psychomotor development}

Children under three years old who present alterations in psychomotor development are often referred to early intervention services, however, from that age onwards, the vast majority are schooled and their follow-up is done by educational institutions. It has been suggested that problems in motor development have negative consequences for their processes of learning, which are related with the chronological age of the child and could be detected in the school ${ }^{4}$.
In this way, in recent decades, psychomotor skills have increased their importance in educational plans, and have among their objectives the development of body organisation and motor skills and the increase of motor efficiency ${ }^{5}$. The necessity of developing psychomotor skills has been justified on the basis of the high prevalence of psychomotor development disorders, estimated to affect between $12-18 \%$ of the child population in developed countries ${ }^{6}$, a figure that increases significantly if behaviour problems and school difficulties are added ${ }^{7,8}$. The disorders of psychomotor development can be defined as an alteration or delay in the progressive acquisition and organisation of psychological and social skills in children, and depend on $75 \%$ of the individual genetic process, and $25 \%$ of environmental stimuli and experience ${ }^{9}$. At the same time, it has been suggested that the main problem in psychomotor delay is determined by the absence of a teaching program in schools ${ }^{10}$.

In this regard, a systematic review reported that more than $60 \%$ of the interventions in the motor development of children result in a statistically significant improvement ${ }^{11}$. However, this same study, the limited quantity and quality of interventions that improve the

1 Facultad Padre Ossó. Universidad de Oviedo. Asturias, España.

Corresponding author: Jose Antonio Prieto Saborit. E-mail: josea@facultadpadreosso.es

Suggested citation: Delgado L, Montes R, Prieto JA. Prevalence of psychomotor retardation and its relation to the sensory profile in preschool children. Prevalence of psychomotor retardation and its relation to the sensory profile in preschool children. $J$ Hum Growth Dev. 26(3): 323-330. Doi: http://dx.doi.org/10.7322/jhgd.122815.

Manuscript submitted: Sep 19 2016, accepted for publication Sep 262016. 
psychomotor development of children in schools stands out, leading to the recommendation that teachers and parents participate in the process of identification and intervention.

\section{Sensory integration}

Within the last lines of intervention, stand out those investigating the stimulation of the sensory modalities for use in the psychomotor practice.

According to several published studies, at least 1 in 20 children's daily lives are affected by a disorder in sensory processing ${ }^{12}$. Another study suggests that 1 in every 6 children experiences enough sensory alterations to interfere negatively in their academic, social and emotional development ${ }^{13}$.

It has been shown that a Sensory Integrative Dysfunction (SID) is the basis of many learning and behavioural disorders, and that a good sensory integration intervention can achieve positive results where traditional therapies have failed ${ }^{14}$. In another study, the implications of sensory processing in social participation in children between six and nine years of age, with and without SID, was investigated, finding significant differences in their relations ${ }^{15}$. More recently, a study revealed that children with SID showed significant differences in functional skills in relation to other children, especially in self-care, mobility and social functions ${ }^{16}$.

\section{Sensory integration-psychomotor development relationship}

After sensory integration therapy was conducted with a group of twenty children diagnosed with high functioning Autism, the results showed a significant improvement in coordination, non-verbal cognitive abilities and the combined sensory-motor and cognitive skills ${ }^{17}$. It has been suggested that the motor impairment in a group of eight children with cerebral palsy, between four and thirteen years, did not respond to a sensory or motor base, but to an alteration in the process of sensory integration ${ }^{18}$.

Sensory processing difficulties are more common in children with disabilities, in particular those with disorders of autism spectrum disorders and attention deficit hyperactivity disorder (ADHD). In these groups of children, there is evidence of an association between difficulties of sensory processing and psychomotor development and behavioural disorders ${ }^{19-21}$. However, research on the specific association between behaviour problems and sensory processing difficulties is scarce in the absence of a diagnosis of these disorders. In this sense, a significant relationship is reported between some skills of sensory integration, such as the visual, and performance of motor skills ${ }^{22}$. The knowledge of the relationship between both variables can contribute not only to improving theoretical models of development, but also to the design of specific interventions in children in typical preschool education.

The aim of the study is to determine the prevalence of psychomotor retardation and the relationship between psychomotor development and sensory integration processes.

\section{METHODS}

\section{Participants and procedure}

A random sample was taken from five schools for pre-school education. The final sample was composed of 66 children, 38 females (57.6\%) and 28 males (42.4\%), with an average age of 4.5 years $(\mathrm{DT}=0.8)$. As inclusion criteria required that participants were aged between 3 and 5 years and did not suffer any diagnosed disability. Four individuals were discarded due to incomplete data.

Initially, 8 preschool centres were contacted, of which 5 accepted participating in the study. A letter of presentation with the main objectives of the study was sent to them, followed by an interview with the management of the centre and the parents association, in which the characteristics of research were exhibited and in which the assessment questionnaires were provided and explained. Two people who knew the protocols of the two scales of assessment presented the study information and the questionnaires. All parents, once informed of the procedure and the objectives of the study, gave their consent in writing.

The study was carried out in compliance with ethical principles of the Declaration of Helsinki and was approved by the Ethics Committee of the Facultad Padre Ossó (Universidad de Oviedo, Spain).

\section{Instruments}

The Observational Scale of Development in its summarised version (EOD-B) was used to assess the level of children's psychomotor development.

The EOD-B consists of seven subscales (first half, second half, second year, third year, fourth year, fifth and sixth year), which determine the psychomotor development of children between one and six years, selecting more discriminative behaviour for a rapid diagnosis. Each subscale assesses eight features of psychomotor development, which, in turn, are composed of different modalities: affectivity, somatic-motricity, sense-motricity, motricity, perceptive-motricity, communication, conceptualization-thought and normativity.

The results of the EOD-B move to a profile of traits, which provides a graphical representation of the percentage of development attained by the child in each trait. From the above, we pooled the outcomes of the EOD-B in the following way: normal development, if the percentage of an achieved trait is between $70-100 \%$; light delay, if it is between $50-69 \%$; moderate delay, if it is between 30 $49 \%$; and severe delay, if it is from $0-29 \%$. Once all of the traits have been categorised, the final result of the scale was structured in the following way: normal development, when all the features are normal or there are only two traits with slight delay; likely delay, when the child has three features with mild delay or to a trait with moderate delay; and delay, for patients who have more than three features with mild delay, more than one trait with moderate delay and/or one or more traits with serious delay.

The EOD-B validation processes have been carried out with ages ranging between zero and six years. The results determined their internal validity (Z-Wilcoxon $\mathrm{p}<0.001)$. 
Furthermore, Sensory Profile (SP) was used to assess the children's sensory processing. This instrument was designed to be used in children from three to ten years of age, both in people without disabilities and in people with autism or attention disorders, and has proven be useful for discriminating differences in processing and sensory integration ${ }^{23,24}$.

The SP is made up of 125 items that are classified into nine factors: sensory seeking, emotionally reactive, low endurance/tone, oral sensory sensitivity, inattention/distractibility, poor registration, sensory sensitivity, sedentary, fine motor. A classification has been proposed by grouping the SP responses as follows: normal sensory profile, when all factors are within the parameters of typical performance or up to two factors probably differ; suspect sensory profile, when three factors probably differ or there is one factor with definite difference; and regulatory disorder, when there are more than three factors with probable difference and/or two or more factors with definite difference ${ }^{25}$. Internal consistency was validated with a Cronbach's Alpha of 0.47 to 0.91 in the sensory sections, and 0.72-0.91 in the factors.

\section{Analysis of data}

Statistical analysis was performed with the statistical package SPSS 20. In the first place, a descriptive statistic of each of the items of the instruments of assessment was made for the total sample. The normality of the distribution of the sample was found using the Levene test. Results (Levene test $p \geq .05$ ) confirmed that the condition of homogeneity of variances was met by using parametric tests in subsequent analyses. Analysis of variance, or ANOVA, was used as the main test for the comparison of means, and the Scheffé test was used as the post-hoc test, or test for multiple comparisons, in cases in which there were more than two different variables.

\section{RESULTS}

The analysis of the variance comparing the means of the development reached in the EOD-B, depending on the type of sensory profile, showed statistically significant differences between the means in three of the eight traits evaluated, with the group of regulatory disorder being shown to make the difference concerning the others two goups through the Scheffé test (Table 1). The traits where differences were found were "somatic-motricity", "communication" and "conceptualization-thought".

Table 2 presents the statistical values $\mathrm{F}$ of scores of the factors and sensory sections of the SP with the psychomotor traits of the EOD-B. It is observed that all of the EOD-B traits evaluated have some degree of relationship with at least a section or the SP factor, with the traits "somatic-motricity", "perceptive-motricity" and "conceptualization-thought" showing a greater number of meaningful relationships with the sensory profile.

Table 1: Distribution of means of the features of the EOD-B depending on the type of sensory profile

\begin{tabular}{lcccc} 
EOD-B & $\begin{array}{c}\text { Normal profile }(n=34) \\
\text { X } \pm \text { DT }\end{array}$ & $\begin{array}{c}\text { Suspect profile }(n=14) \\
\text { X } \pm \text { DT }\end{array}$ & $\begin{array}{c}\text { Regulatory disorder }(n=18) \\
\text { X } \pm \text { DT }\end{array}$ & Sig. \\
Affectivity & $.70 \pm .95$ & $.50 \pm .94$ & $1.00 \pm 1.18$ & .378 \\
Somatic-motricity & $.43 \pm .72$ & $.50 \pm .85$ & $1.22 \pm .73$ & $.003^{\star}$ \\
Sense-motricity & $.00 \pm .00$ & $.00 \pm .00$ & $.00 \pm .00$ & - \\
Motricity & $.40 \pm .77$ & $.64 \pm .92$ & $.77 \pm .80$ & .285 \\
Perceptive-motricity & $.10 \pm .30$ & $.21 \pm .57$ & $.50 \pm .85$ & .073 \\
Communication & $.20 \pm .40$ & $.42 \pm .64$ & $.66 \pm .68$ & $.023^{\star}$ \\
Conceptualization-thought & $.03 \pm .18$ & $.14 \pm .36$ & $.55 \pm .98$ & $.011^{*}$ \\
Normativity & $.06 \pm .25$ & $.50 \pm .54$ & $.27 \pm .90$ & .297 \\
\hline
\end{tabular}

Significance level in the differences, ANOVA $\left({ }^{*} p<.05,{ }^{* *} p<.001\right)$

Table 2: F statistical factors and sections of SP depending on the features of the EOD-B

$\begin{array}{lcccccccc}\text { Sensorial profile } & \text { Affective } & \text { Somatic motor } & \text { Perceptive-sense } & \text { Motor } & \text { Perceptive-motor } & \text { Communication } & \begin{array}{c}\text { Conceptualisation- } \\ \text { thought }\end{array} \\ & & & & & & & & \\ \text { Normativity }\end{array}$




\begin{tabular}{|c|c|c|c|c|c|c|c|c|}
\hline Sensorial profile & Affective & Somatic motor & Perceptive-sense & Motor & $\begin{array}{l}\text { EOD-B } \\
\text { Perceptive-motor }\end{array}$ & Communication & $\begin{array}{c}\text { Conceptualisation- } \\
\text { thought }\end{array}$ & Normativity \\
\hline $\begin{array}{l}\text { Sensory processing related } \\
\text { to endurance/tone } \\
\text { Modulation related to body }\end{array}$ & 1.06 & $13.97^{\star \star}$ & - & $3.25^{\star}$ & .14 & .20 & 1.67 & 2.35 \\
\hline $\begin{array}{l}\text { position and movement } \\
\text { Modulation of movement }\end{array}$ & 2.31 & $5.50 *$ & - & $3.32^{*}$ & .15 & .23 & .90 & .08 \\
\hline $\begin{array}{l}\text { affecting activity level } \\
\text { Modulation of sensory } \\
\text { information that affects }\end{array}$ & 2.49 & 1.94 & - & 1.68 & .72 & .82 & .06 & .59 \\
\hline $\begin{array}{l}\text { emotional reactions } \\
\text { Modulation of sensory } \\
\text { input affecting emotional }\end{array}$ & $5.00 *$ & $7.67^{\star *}$ & - & $4.01^{*}$ & 1.02 & 1.08 & $6.81^{*}$ & .84 \\
\hline $\begin{array}{l}\text { responses } \\
\text { Modulation of visual input } \\
\text { affecting emotional }\end{array}$ & .61 & 1.02 & - & .31 & $5.24^{*}$ & 1.13 & 2.13 & .70 \\
\hline $\begin{array}{l}\text { responses and activity level } \\
\text { Behavioral outcomes of }\end{array}$ & $3.64^{*}$ & $5.53^{*}$ & - & .21 & 2.61 & .57 & $5.75^{\star}$ & 1.18 \\
\hline $\begin{array}{l}\text { sensory processing } \\
\text { Items indicating thresholds }\end{array}$ & 2.47 & $3.85^{\star}$ & - & .25 & $5.70 *$ & 1.19 & $6.69 *$ & 1.13 \\
\hline of response & 2.19 & $3.05^{\star}$ & - & $4.08^{*}$ & $3.58 *$ & .733 & .18 & .65 \\
\hline
\end{tabular}

Significance level in the differences, ANOVA $\left({ }^{*} p<.05,{ }^{* \star} p<.001\right)$.

Table 3: Distribution of means of sensory profile based on the overall psychomotor development

\begin{tabular}{ccccc} 
& Normal development $(n=31)$ & Probable delay $(n=17)$ & Retardation $(n=14)$ & Sig. \\
$X$ & $\pm D T$ & $X \pm D T$ & $1.36 \pm .84$ & $.001^{*}$ \\
\hline Sensory profile & $.42 \pm .67$ & $1.06 \pm .89$ & 1.89 & \\
\hline
\end{tabular}

Level of significance in the differences, ANOVA test $\left({ }^{*} p<0.05,{ }^{* *} p<.001\right)$.

Table 4: Percentage distribution of development in every feature of the EOD-B

\begin{tabular}{lcccc} 
& $\begin{array}{c}\text { Normal Development } \\
(\%)\end{array}$ & $\begin{array}{c}\text { Slight delay } \\
(\%)\end{array}$ & $\begin{array}{c}\text { Moderate Retardation } \\
(\%)\end{array}$ & $\begin{array}{c}\text { Severe Retardation } \\
(\%)\end{array}$ \\
Affectivity & 56.5 & 24.2 & 8.1 & 11.3 \\
Somatic-motricity & 51.6 & 32.3 & 12.9 & 3.2 \\
Sense-motricity & 100.0 & - & - & - \\
Motricity & 62.9 & 19.4 & 16.1 & 1.6 \\
Perceptive-motricity & 82.3 & 12.9 & 3.2 & 1.6 \\
Communication & 66.1 & 29.0 & 4.8 & - \\
Conceptualization-thought & 85.5 & 11.3 & 3.2 & - \\
Normativity & 84.8 & 12.1 & 3.00 & - \\
\hline
\end{tabular}

The "poor registration" factor and the "modulation of sensory input affecting emotional responses" section were those most related to the psychomotor features explored with the EOD-B, by $62 \%$ and $50 \%$ respectively. At the same time, the features "communication" and "normativity", and sections of factors of SP "sensory seeking", "inattention/distractibility", "vestibular processing" and "modulation of movement affecting activity level" showed little or no relationship with the SP or EOD-B, respectively.

On the relationship between global psychomotor development with the sensory profile, the variance analysis showed a statistically significant relationship between normal development, likely delay and delay and the sensory profile, by using the Scheffé test $(\mathrm{p}<.001)$.

An estimate of the percentage of children who had normal development, likely to delay and delay in the features of the EOD-B was carried out. Table 4 shows that the "sense-motricity" trait was found in normal development in all of the sample, and that the features features "conceptualization-thought" and "normativity" have higher frequency of normal development. The traits most affected were the "affectivity" and "somatic-motricity".

In terms of the overall results of the EOD-B, 14 children $(22 \%)$ were found in the psychomotor delay group; 17 children $(27 \%)$ in the likely psychomotor delay group; and 31 children $(50 \%)$ in the normal development group.

An estimate of the percentage of children presenting typical performance, probable differences and defined difference in sections and factors of SP was made. The "modulation of sensory input affecting emotional responses" section was the most affected, with more than $50 \%$ of the sample outside typical performance. At the same time, the features "communication" and "normativity", and sections of factors of SP "sensory seeking”, "inattention/distractibility", "vestibular processing" and "modulation of movement affecting activity level" showed little or no relationship with the SP or EOD-B, respectively. Regarding 
the factors "inattention/distractibility" and "sensory seeking", these had a higher frequency of profiles with likely dysfunction, while "sensory sensitivity" and "sedentary" were factors with more than $84 \%$ of the sample within the typical values.

In terms of the overall results the SP sample, 18 children $(27.2 \%)$ were found in the group of regulatory disorder; 14 children $(21.2 \%)$ in the group of suspected profile; and $34(51.5 \%)$ children in the group of normal profile.

\section{DISCUSSION}

The results of this study in Spain suggest that the prevalence of psychomotor retardation is $22 \%$. These data are slightly above the international indicators, which estimate it at around $12-18 \%{ }^{6}$. Studies conducted in different countries show psychomotor delay in between 29 and 60 per cent of children ${ }^{26}$. However, these results are not extrapolated to the Spanish population, due to their different socio-demographic characteristics ${ }^{27}$.

If the traits of the EOD-B are analysed individually, it is possible to see that the alteration of the development of a trait is not directly related to a change in global psychomotor profile, since $74.19 \%$ of the sample is delayed in at least one trait, while the percentage of psychomotor retardation stands at $22 \%$.

A recent study evaluated the psychomotor performance of 367 children of preschool education in five areas: grip, visual-motor integration, posture, movement and handling of objects ${ }^{28}$. Results showed no significant difference in the overall performance according to gender.

Regarding disorders of sensory integration, the present study found the prevalence of children with regulatory disorder to be $30 \%$. These results are clearly above some studies that have defined the prevalence around $5-10 \%$, and above the upper limit of other recent studies that have estimated the prevalence of regulatory disorders between $12-30 \%{ }^{12,26}$.

The factors of sensory processing with highest percentage of typical performance were "sensory sensitivity", "low endurance/tone", "poor registration" and "sedentary", while those that presented greater alteration were "sensory seeking" and "inattention/ distractibility". These findings are similar to other studies, which placed "Iow endurance/tone", "sensory sensitivity" and "poor registration" as factors with more typical performance, and "sensory seeking" and "inattention/ distractibility" as factors with higher percentage of regulatory disorder25. A similar situation occurs with respect to sensory modulation, where "visual processing" and "sensory processing related to endurance/tone" sections were the ones with a higher percentage of typical performance, while "modulation of sensory input affecting emotional responses" was found to be most altered.

The most notable differences found between the two studies were in the percentage distribution of the typical performance in the section "behavioral outcomes of sensory processing", Castillejos and Rivera found this to be $50 \%$, in contrast to the $75.8 \%$ found in our study.

The relationship between the psychomotor development and sensory processing has been found both in the analysis of each trait of the EOD-B with each factor and section of the SP, as in the analysis of the global development with the resulting sensory profile. It has been suggested that children identified with the SP regulatory disorder were more likely to present deficits in their motor skills and processing, as well as experiencing more difficulties in carrying out their daily occupations ${ }^{29}$. In this sense, the influence of early experience in the development of sensory systems has been studied, noting the importance of providing sensory stimuli through activities and psychomotor performance, in order to develop neural patterns ${ }^{30}$. A recent study investigated the functional differences between children with SPD, physical disability and typical development. The results showed that children with SPD showed significant differences with respect to the children from other groups in functional skills, especially in self-care, mobility and social functions ${ }^{16}$.

Regarding the relationship between each psychomotor trait and sections and factors of the SP, the results of this study show that the "poor registration" factor and the "modulation of sensory input affecting emotional responses" section were related to most of the psychomotor features explored with the EOD-B. At the same time, the features "communication" and "normativity", and the sections or factors of SP "sensory seeking", "inattention/ distractibility", "vestibular processing" and "modulation of movement affecting activity level" showed little or no relationship with the SP or EOD-B respectively.

The results are significantly different from those found in other studies, in which the largest number of relationships were found in sections of "sensory processing related to endurance/tone" and "modulation related to body position and movement", while gross motor-related areas and sections of the SP "visual processing", "modulation of movement affecting activity level" and "modulation of visual input affecting emotional responses and activity level" and "modulation of movement affecting activity level", which did not show or showed very low ratio with the SP or psychomotor development respectively ${ }^{25}$. However, taking as a reference the resulting sensory profile and comparing it with every feature of the EOD-B, results are, similar to the previous study in terms of disorder regulatory, relationship with alteration or deficits in communication features.

Finally, the results of this study show differences in the distribution of the psychomotor profile and sensory profile depending on the age of the child. These data corroborate those obtained in other investigations. Other studies have shown differences in psychomotor performance in a sample of children between three and five years, with similar characteristics to the sample of this $\operatorname{research}^{28}$. Its findings suggested that age significantly influences motor performance. With regards to sensory processing, previous research studied the influence of age on the sensory integrative functions in a sample of 1,000 Taiwanese children classified into groups according to their age ${ }^{31}$. Their sensory processing was assessed using the Test of Sensory Integration Function (TSIF), a stand- 
ardised test in the diagnosis of sensory integrative dysfunction. Analysis of variance revealed that age is a significant factor in each of the areas of sensory integration associated with various stages of development. For the subscale "sensory modulation" and "emotional behaviour", the differences between the ages were only a significant factor among children 3-4 years and children 5-6 years, results similar to those obtained in this study. The highest prevalence of alterations in sensory processing in children under five years coincides with the traditional scientific literature and is probably due to the immaturity of neural circuits in the nervous system and sensory integration system ${ }^{32}$.

The main limitations of this study are as follows: First, the sample size does not allow for generalisation of the results obtained, or for stratifying them according to gender and age with a high rate of reliability. Although prevalence data may be suggested by the instruments, it is necessary to engage in follow-up studies to determine sensory processing and psychomotor development. Moreover, this study has not assessed the presence or absence of other dysfunctions, beyond impaired psychomotor development and sensory integrative dysfunction.

The main strength of this study lies in its novelty when it comes to investigating the sensory profile as a possible cause of psychomotor retardation in the members of the population that do not have disabilities, confirming, thus, the need not only of permanent stimulation but also its correct assessment.

In conclusion, the data provided in this study indicate a high prevalence of psychomotor retardation in children of 3-5 years, mainly in motor-somatic and affective traits. The sensory profile showed the presence of regulatory disorders in $30 \%$ of the sample. There is a significant association between the presence of psychomotor disorders and sensory processing $(\mathrm{p}=0.001)$.

These results have important implications for preschools and schools, highlighting the need to assess and intervene in the psychomotor development of the child in a very defined and structured way from within the educational field, for this is required knowledge of the developmental psychology and educational psychology ${ }^{33}$. At the same time, these results present the sensory profile as a possible line of intervention for achieving children's correct psychomotor development.

At same time, the results of this study contribute to the field of public health, demonstrating the need for follow-ups of children with typical development and without disability. These children may have disorders in psychomotor development due to a lack of appropriate action, which would lead to significant alterations in their evolutionary development, and therefore in their health.

\section{REFERENCES}

1. Bornstein $\mathrm{MH}$, Hendricks C. Screening for developmental disabilities in developing countries. Soc Sci Med. 2013;97:307-15. DOI: http://dx.doi.org/10.1016/j.socscimed.2012.09.049

2. Rosa Neto F, Santos APM, Xavier RFC, Amaro KN. A Importânia da avaliação motora em escolares: análise da confiabilidade da Escala de Desenvolvimento Motor. Rev Bras Cineantropom Desempenho Hum. 2010;12(6):422-7. DOI: http://dx.doi.org/10.5007/1980-0037.2010v12n6p422

3. Cardoso AA, Magalhães LC, Barbosa VM. Desenvolvimento psicomotor em crianças pré-termo e a termo na idade escolar. Rev Bras Desenvolvimento Hum. 2011;21(2):210-19. DOI: http://dx.doi.org/10.7322/ jhgd.20009

4. Carboni-Román A, del Río Grande D, Capilla A, Maestú F, Ortiz T. Bases neurobiológicas de las dificultades de aprendizaje. Rev Neurol. 2006;42(Supl.2):S171-5.

5. Sassano M. La escuela: un nuevo escenario para la psicomotricidad. Rev Iber Psicom Tec Corp. 2003;(11):77-98.

6. Avaria MA. Pediatría del desarrollo y comportamiento. Rev Ped Elec. 2005;2(1):88-91.

7. Glascoe FP. Early detection of developmental and behavioral problems. Ped Rev. 2000;21(8): 272-80.

8. Lecannelier F, Ewert JC, Groissman S, Gallardo D, Bardet A M, Bascuñan, A, et al. Validación del Inventario de Conductas Infantiles para niños de entre 11/2-5 años (CBCL 11/2-5) en la Ciudad de Santiago de Chile. Univer Psychol. 2014;13(2):491-500.

9. Doussoulin, S. Influencia del nivel socioeconómico y la estimulación ambiental en el desarrollo psicomotor en preescolares. Kinesiologia. 2003;70:15-7.

10. Nobre FSS, Coutinho MTC, Valentini NC. The ecology of motor development in coastal school children of brazil northeast. J Hum Growth Dev. 2014;24(3):263-73. DOI: http://dx.doi.org/10.7322/jhdg.88910

11. Riethmuller AM, Jones RA, Okely AD. Efficacy of interventions to improve motor development in young children: a systematic review. Pediatrics. 2009;124(4): e782-92. DOI: http://dx.doi.org/10.1542/peds.20090333.

12. Ahn RR, Miller LJ, Milberger S, Mclntosh DN. Prevalence of parents' perceptions of sensory processing disorders among kindergarten children. Am J Occup Ther. 2004;58(3):287-93. DOI: http://dx.doi. org/10.5014/ajot.58.3.287

13. Ben-Sasson A, Carter AS, Briggs-Gowan MJ. Sensory over-responsivity in elementary school: prevalence and social-emotional correlates. J Abnorm Child Psychol. 2009;37(5):705-16. DOI: http://dx.doi. org/10.1007/s10802-008-9295-8

14. Roley SS, Blanche EI, Schaaf RC. Understanding the nature of sensory integration with diverse populations. San Antonio: Therapy Skill Builders: 2001. 
15. Cosbey J, Johnston SS, Dunn ML. Sensory processing disorders and social participation. Am J Occup Ther. 2010;64(3):462-73. DOI: http://dx.doi.org/10.5014/ajot.2010.09076

16. Armstrong DC, Redman-Bentley D, Wardell M. Differences in function among children with sensory processing disorders, physical disabilities, and typical development. Pediatr Phys Ther. 2013;25(3):315-21. DOI: http://dx.doi.org/10.1097/PEP.0b013e3182980cd4

17. Iwanaga R, Honda S, Nakane H, Tanaka K, Toeda H, Tanaka G. Pilot study: efficacy of sensory integration therapy for Japanese children with high-functioning autism spectrum disorder. Occup Ther Int. 2014;21(1):4-11. DOI: http://dx.doi.org/10.1002/oti.1357

18. Gordon AM, Charles J, Steenbergen B. Fingertip force planning during grasp is disrupted by impaired sensorimotor integration in children with hemiplegic cerebral palsy. Pediatr Res. 2006;60(5):587-91. DOI: http://dx.doi.org/10.1203/01.pdr.0000242370.41469.74

19. Tomchek SD, Huebner RA, Dunn W. Patterns of sensory processing in children with an autism spectrum disorder. Res Autism Spectr Disord. 2014;8(9):1214-24. DOI: http://dx.doi.org/10.1016/j.rasd.2014.06.006

20. Yochman A, Parush S, Ornoy, A. Responses of preschool children with and without ADHD to sensory events in daily life. Am J Occup Ther. 2004;58(3):294-302.

21. Ashburner J, Ziviani J, Rodger S. Sensory processing and classroom emotional, behavioral, and educational outcomes in children with autism spectrum disorder. Am J Occup Ther. 2008;62(5):564-573. DOI: http://dx.doi.org/10.5014/ajot.62.5.564

22. Pereira DM, Araújo RCT, Braccialli LMP. Análise da relação entre a habilidade de integração visuo-motora e o desempenho escolar. Rev Bras Desenvolvimento Hum. 2011; 21(3): 808-17. DOI: http://dx.doi. org/10.7322/jhgd.20033

23. Dunn W, Westman K. The sensory profile: the performance of a national sample of children without disabilities. Am J Occup Ther. 1997;51(1):25-34.

24. Kientz MA, Dunn W. A comparison of the performance of children with and without autism on the sensory profile. Am J Occup Ther. 1997;51(7): 530-7.

25. Castillejos-Zenteno L, Rivera-González R. Asociación entre el perfil sensorial, el funcionamiento de la relación cuidador-niño y el desarrollo psicomotor a los tres años de edad. Salud Ment. 2009;32(3):231-9.

26. Contreras GB, Fernández L, Coma J. Estimulación temprana y desarrollo de la inteligencia. Pediatr Día. 2003;19(4):27-31.

27. Pascucci MC, Lejarraga H, Kelmansky D, Álvarez M, Boullón M, Breiter P, et al. Validación de la prueba nacional de pesquisa de trastornos de desarrollo psicomotor en niños menores de 6 años. Rev Chil Pediatr. 2004; 75(1):75-6. DOI: http://dx.doi.org/10.4067/S0370-41062004000100012

28. Saraiva L, Rodrigues LP, Cordovil R, Barreiros J. Influence of age, sex and somatic variables on the motor performance of pre-school children. Ann Hum Biol. 2013;40(5):444-50. DOI: http://dx.doi.org/10.3109/030 14460.2013.802012

29. White BP, Mulligan S, Merrill K, Wright J. An examination of the relationships between motor and process skills and scores on the sensory profile. Am J Occup Ther. 2007;61(2):154-60. DOI: http://dx.doi. org/10.5014/ajot.61.2.154

30. Grubbs MS, Thompson ID. The influence of early experience on the development of sensory systems. Curr Opin. Neurobiol. 2004;4(4):503-12. DOI: http://dx.doi.org/10.1016/j.conb.2004.06.006

31. Lin CK, Wu HM, Wang HY, Tseng MH, Lin CH. Age as a factor in sensory integration function in Taiwanese children. Neuropsychiatr Dis Treat. 2013;9:995-1001.DOI: http://dx.doi.org/10.2147/NDT.S49514

32. Bundy AC, Murray EA, Lane SJ. Sensory integration: theory and practice. 2nd ed. Philadelphia: Davies Company; 2002.

33. González-Moreno CX, Solovieva Y, Rojas LQ. Actividad reflexiva en preescolares: perspectivas psicológicas y educativas. Univ Psychol. 2011;10(2):423- 440.

This article is distributed under the terms of the Creative Commons Attribution 4.0 International License (http://creativecommons.org/licenses/by/4.0/), which permits unrestricted use, distribution, and reproduction in any medium, provided you give appropriate credit to the original author(s) and the source, provide a link to the Creative Commons license, and indicate if changes were made. The Creative Commons Public Domain Dedication waiver (http://creativecommons.org/publicdomain/zero/1.0/) applies to the data made available in this article, unless otherwise stated. 


\section{RESUMEN}

Los niños de preescolar con desarrollo típico no tienen un seguimiento de su desarrollo psicológico y motor desde el ámbito educativo. El objetivo de este estudio fue determinar la prevalencia en el retraso psicomotor y la relación entre el desarrollo psicomotor y los procesos de integración sensorial en niños de 3 a 5 años de edad. La muestra estuvo formada por 66 niños de Preescolar con una edad media de 4.2 años. Se les aplicó la Escala del Desarrollo Observacional en su versión breve (EOD-B) y el Perfil Sensorial (SP). El ANOVA reveló una alta asociación entre la presencia de alteraciones psicomotoras y de procesamiento sensorial $(p=0.001)$. Además, los datos revelaron una alta prevalencia de trastornos regulatorios en el perfil sensorial (30\%) y de retraso psicomotor (20\%). Los resultados abren nuevas líneas de investigación e intervención en desarrollo psicomotor dentro del marco educativo.

Palabras-clave: desarrollo psicomotor, integración sensorial, educación preescolar. 